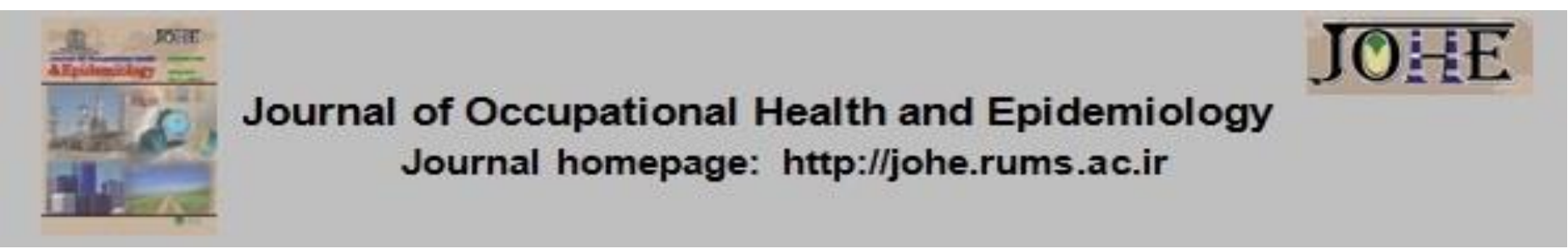

\title{
Challenges Facing the Health System in Responding to Mining Accidents: The Case of the Zemestan-Yurt Mine Explosion in Iran (2017)
}

\author{
Moslem Sarani ${ }^{1}$, Mohammadreza Honarvar ${ }^{2}$, Ali Sahebi ${ }^{3}$, Meysam Safi-Keykaleh ${ }^{4}$, Saeedeh \\ Nateghinia ${ }^{5}$, Katayoun Jahangiri $6^{*}$
}

1. PhD Candidate in Health in Disasters and Emergencies, Dept. of Health in Emergencies and Disasters, School of Public Health and Safety, Shahid Beheshti University of Medical Sciences, Tehran, Iran.

2. Assistant Prof., Health Management and Social Development Research Center, Golestan University of Medical Sciences, Gorgan, Iran.

3. PhD in Health in Disasters and Emergencies, Non-Communicable Diseases Research Center, Ilam University of Medical Sciences, Ilam, Iran.

4. Assistant Prof., Nahavand School of Allied Medical Sciences, Hamadan University of Medical Sciences, Hamedan, Iran.

5. PhD in Industrial Management, Skull Base Research Center, Loghman Hakim Hospital, Shahid Beheshti University of Medical Sciences, Tehran, Iran.

6. Professor, Dept. of Health in Emergencies and Disasters, School of Public Health and Safety, Shahid Beheshti University of Medical Sciences, Tehran, Iran.

Citation: Sarani M, Honarvar M, Sahebi A, Safi-Keykaleh M, Nateghinia S, Jahangiri
K. Challenges Facing the Health System in Responding to Mining Accidents: The Case of the
Zemestan-Yurt Mine Explosion in Iran (2017). J Occu Health Epidemiol 2021; 10(3):204-8.

\section{Article Info}

* Corresponding author:

Katayoun Jahangiri,

E-mail:

k.jahangiri@sbmu.ac.ir

\section{Article history}

Received: Aug 2021

Accepted: Nov 2021

$10.52547 /$ johe.10.3.204

Print ISSN: 2251-8096 Online ISSN: 2252-0902

Peer review under responsibility of Journal of Occupational Health and Epidemiology

\begin{abstract}
Background: Occupational accidents cause death and disabilities among millions of workers around the world. The mining industry is among the riskiest occupations in this respect. This study aims to investigate interventions made and challenges faced by the health system in response to the Zemestan-Yurt Mine explosion in the Golestan Province, Iran, 2017.

Materials and Methods: In this article, being a field report, data were collected through direct observations and interviews with first responders involved in the response process, and by checking national and local reports from other organizations.

Result: On Wednesday, May 4, 2017, at 11:58 AM, an explosion occurred in the Yurt coal mine, Golestan Province, in which 126 people were affected directly or indirectly. In fact, 43 workers were killed immediately after the explosion of a coal wagon, 55 were dispatched to hospitals, and 28 received outpatient health services. In this incident, more than 100 teams from various organizations, including the health system, arrived at the scene and carried out relief and rescue operations.

Conclusions: The results of the current study indicate that the health system does not have specific instructions, training plans, as well as well-trained and prepared personnel for managing mine-related accidents. Besides, interactions are not integrated and coordinated among disaster management response teams. Therefore, developing preparedness instructions for responding to disasters, forming rapid response teams and training them for industrial accidents, as well as performing joint exercises and drills with responsible organizations can be effective in improving responses to such accidents.
\end{abstract}

Keywords: Health System, Health Services, Occupational Accidents, Explosions, Iran.

\section{Introduction}

Occupational accidents cause death and disabilities among millions of workers around the world [1]. Coal miners are more prone to workrelated accidents than others due to the nature of the work and the equipment required [2]. Such 
careers impose significant physical, psychological, social, and economic burdens on workers' life. According to the International Labor Organization (ILO), approximately 333 million occupational accidents occur worldwide each year, about 163 million workers suffer from occupational diseases, and about two million of them die from various diseases [3]. Mining, among dangerous jobs, is one of the occupations with most frequent fatal accidents [4]. Factors, such as ignorance of work safety standards by mine owners and miners, inattentiveness to risk factors at work, carelessness in using personal protective equipment, and disregard for environmental hazards produce adverse outcomes $[5,6]$. In the Iranian health system, the "Environmental and Occupational Health Bureau" of the Ministry of Health $(\mathrm{MoH})$ bears the main responsibility for responding to mine-related accidents. This line responsibility (environmental units) rests with environmental and occupational health units in the health department of medical universities [6].

Although the Iranian health system has defined protocols and specific trainings required to respond to natural disasters, they seem to be inapplicable to industrial and manmade disasters. This is because the nature and consequences of these types of disasters vary significantly in the affected community [7, 8]. Occupational and industrial accidents occur frequently, so responding to them pose many challenges to the health system. Since these events have not been reported in detail yet, the research team decided to examine the responses given by the health system to challenges in managing the explosion of the "Zemestan-Yurt" mine in the Golestan province, Iran, 2017, to be used as lessons learned for similar future cases.

\section{Materials and Methods}

The present research, being a field report, aims to identify operational challenges of the healthcare teams in analyzing the problems encountered in response to the Zemestan-Yurt Mine explosion in Iran. Data were collected through direct observations and interviews with first responders involved in the response process as well as checking national and local reports from other organizations. Data accuracy was verified by holding a meeting with the participants in the health system responding to the explosion. Besides, the results were compared with reports from other agencies involved in the relief operation to determine if there were any disagreements or conflicts of interest. This study was approved by the Skull Base Research Center, Loghman Hakim Hospital, Shahid Beheshti University of Medical Sciences, Tehran, Iran, under ethical code IR.SBMU.RETECH.REC.1400.088.

\section{Results}

On Wednesday, May 4, 2017, at 11:58 AM, an explosion occurred in the Zemestan-Yurt coal mine in the north of Iran (Fig. 1). Immediately after the accident, 21 coal miners lost their lives due to the blast, with a number of other miners trapped at the depth of 1,300 meters, in a space full of carbon monoxide and methane. Following the explosion, in an emotional endeavor without following safety procedures, 22 experts and their colleagues entered the mine and lost their lives due to toxic gas inhalation, raising the total death toll to 43 . Having heard the explosion, people from the surrounding villages attended the scene. A number of people arrived at the scene out of curiosity, and some organizations reached there to help.

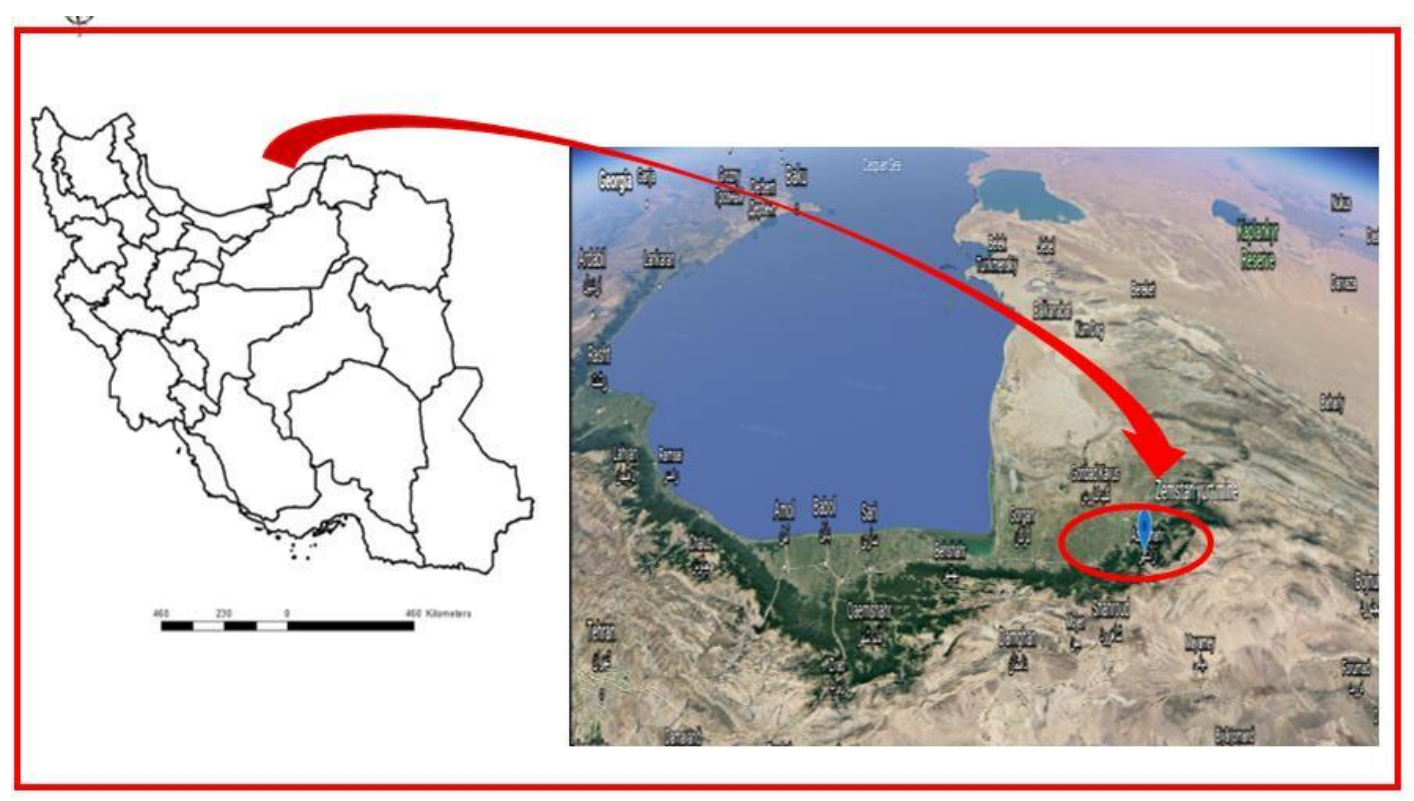

Fig.1. The Zemestan-Yurt coal mine as located in Iranian references 
Time intervals of the responding organizations Thirty-two minutes after the mine explosion: The police arrived at the scene to evacuate unrelated people and disperse the dense population as the first operations. Simultaneously, the crisis management team of the provincial government, as the main coordinator of crises and disasters, arrived at the scene.

Ten minutes later: Local health personnel, including Emergency Medical Services (EMS) and primary healthcare staff, doctors, and nurses were dispatched to the scene. Accordingly, the health system response started with the formation of the Incident Command System (ICS) to define and assign related tasks to all personnel.

Ten minutes after health staff arrival: The firefighting team, Red Crescent staff, volunteers, and miners' families reached the scene.

Problems of early hours: The gathering of nonexpert spectators who just arrived out of curiosity to watch the incident made it difficult for the responding entities to carry out their operations. Some individuals and organizations attending the scene would cause congestion, rather than help, because they were not experienced in responding appropriately to the event. Many of the activities done were inappropriate or parallel to those of other agencies. Besides, many of the equipment brought to the scene were not suitable for rescuing the people trapped in the mine and helping the injured. Additionally, dead body management became difficult due to the lack of a proper morgue for storing the dead. There was no coordinated plan for managing the presence of individuals, organizations, and volunteers, which led to the useless aggregation and confusion of onlookers and caused delays in response operations. Many individuals and organizations would not obey orders issued by senior coordinators and just played a show-off role.

Activities and initiatives: Within two weeks from the explosion, 83 responders were injured or intoxicated due to the gathering of a large number of people from various organizations, who were treated by the medical team. The process of providing relief at the scene immediately started by the EMS technicians with the collaboration of volunteers, including the mine staff, Red Crescent volunteers, residents of the neighboring village, and miners' families.

An Incident Command Post (ICP) was deployed 20 meters from the entrance to the mine hole to provide relief and medical services for the initial triage. Since the miners were deeply trapped in a space full of carbon monoxide and methane, the injured workers' contaminated clothes were removed by community volunteers and relief forces. Next, the injured miners were transferred out of the tunnel to a place assigned for providing them with Simple Triage and Rapid Treatment (START) services. Besides, injured workers with red and yellow tags were transported to another location (15 meters away from the triage site) for secondary triage and then to the hospital. Injured workers with green tags were transported by private vehicles to the district hospital in coordination with the triage officer. In addition, an operational health team consisting of public health experts and paramedics was dispatched to the scene the day after the incident to collect and update field data. All reports were sent via email and in hard copies to the field commander in the ICP. Next, the collected incident data were reported to the university emergency operation center (EOC) and the district hospital. Necessary coordination was established with other internal and external departments, such as the Red Crescent, the incident commander, and the mine authorities.

\section{Discussion}

The findings of this study indicate disparities in addressing mining accidents by the health system. Against this backdrop, the present study aims to investigate the performance and efficacy of disaster management organizations in unstable situations. Besides, this study provides insights into the way the health system can be more resilient during disastrous incidents. As reported, more than 126 workers were affected by the accident, with 43 of whom having lost their lives. Beside, more than 83 volunteers participating in the relief operations were injured and carried to hospitals (55 volunteers to the hospital of Azadshahr Town [the affected area] and 28 to the adjacent hospitals). According to the results of the present study, the health system needs to be more prepared for giving appropriate responses to the hazards posed by mining activities. However, other disaster-response agencies did not act better and had similar problems. In fact, preparedness requires having a well-developed and well-taught plan, educated and knowledgeable personnel, and up-to-date and appropriate equipment. However, the disaster response organizations had fundamental weaknesses in all components of preparedness, according to the results of this study.

The reason for this inconsistency could be attributed to the lack of a joint inter-organizational response plan and effective training programs. Similarly, Mohajer-Vatan in a study addressed this issue by evaluating the response of the pre- 
hospital system to the Zemestan-Yurt Mine explosion [9]. In the mentioned study, the main problems were reported as the lack of organizational coordination and suitable equipment, being consistent with our findings. In another study, Karen et al (2009) explored the role of mining companies in accidents to create a framework for thinking about organizational accidents from a structural perspective, with an emphasis on regulations and legislation processes employed in risky careers [10]. Iran has been using mining resources for some decades. Although the trend of events in mine accidents is predictable, there is no integrated structure for coordinating the responses of the organizations involved in such accidents. As mentioned in the introduction, the "Environmental and Occupational Health Bureau" and occupational health units of health deputies at medical universities are responsible for overseeing miners' health [6]. Although these units conduct inspections at regular intervals to assess coal miners' health status, it appears that no specific preventive program has been developed for these units to avoid industrial disasters. Accordingly, legislation gaps are among the most challenging issues contributing to mine accidents. In terms of training and experience, the health system personnel have not been adequately trained to deal with such incidents. Kathleen et al (2010) conducted a qualitative study in Sweden to explore prehospital staff's experiences in dealing with mine explosions. According to their findings, most problems were related to issues, such as the existence of a chaos in a strange, uncontrolled, and insecure environment, having a passive role in the rescue team, as well as the lack of specific task descriptions and adequate training. These results were consistent with our findings because a large number of the personnel who participated in the Yurt explosion response operations had never attended a similar scene and were not trained for such incidents [11, 12]. Given that numerous organizations and volunteers attended the scene of the incident, factors, such as the lack of coordination as well as inadequate inter- and intraorganizational communication were the serious challenges posed. Accordingly, boosting inter- and intra-organizational coordination could increase the quality of services and effectiveness of response measures in disasters [5, 13]. The ICS uses a command structure to give a standard response at the scene of the accident, being able to fulfil the requirements of an emergency situation by integrating the responses of different organizations [14]. Therefore, to achieve coordination between and within sectors involved in providing relief services, it is necessary to strengthen the ICS (based on potential risks) by conducting joint exercises in the preparation phase [15].

\section{Conclusion}

The results of the current study showed that the health teams on the scene were not well prepared to give appropriate responses to mine-related accidents. Besides, interactions between response teams in the disaster management unit were not integrated and coordinated. In view of the foregoing, developing a preparedness plan, boosting inter- and intra-organizational interactions, training personnel for mine-related accidents, and holding joint exercises and drills with responsible organizations could help improve response measures.

\section{Acknowledgement}

This study was approved by the Skull Base Research Center, Loghman Hakim Hospital, Shahid Beheshti University of Medical Sciences, Tehran, Iran.

Conflict of interest: None declared.

\section{References}

1. Jahangiri K, Ghodsi H, Khodadadizadeh A, Youse Nezhad S. Pattern and nature of Neyshabur train explosion blast injuries. World $\mathrm{J}$ Emerg Surg 2018; 13:3.

2. Khodabandeh S, Haghdoost AA, Khosravi Y. Epidemiology of work-related Accidents in Kerman Coal Mines during 1991-2006. Iran Occup Health J 2012; 8(4):18-28.

3. Noorini M. Study of the trend of mining health and safety during 2011 to 2016 [Internt]. Available from; https://www.amar.org.ir/Portals/0/News/1397/re port_safety_madan(1390-1395).pdf

4. Bagherpour R, Yarahmadi R, Khademian A. Safety Risk Assessment of Iran's Underground Coal Mines Based on Preventive and Preparative Measures. Hum Ecol Risk Assess 2015; 21(8):2223-38 .

5. Brnich MJ, Kowalski-Trakofler KM. Underground Coal Mine Disasters 1900-2010: Events, Responses, and a Look to the Future. Extracting the Science: A Century of Mining Research. Atlanta, Georgia, United States The National Institute for Occupational Safety and Health (NIOSH), Centers for Disease Control and Prevention; 2010 Jan. 11 p. Report No.:20036849.

6. Donoghue AM. Occupational health hazards in mining: an overview. Occup Med (Lond) 2004; 54(5):283-9

7. Yousefian S, Sohrabizadeh S, Jahangiri K. Identifying the components affecting intra- 
organizational collaboration of health sector in disasters: providing a conceptual framework using a systematic review. Int J Disaster Risk Reduct 2021; 57:102146.

8. Center of Environmental and Occupational Health, Ministry of Health \& Environmental Research Institute of Tehran University of Medical Sciences. A guide and instructions to occupational health for miners' health. 2011. Available from: https://markazsalamat.behdasht.gov.ir/uploads/ bh2_madan_171961.pdf

9. Raeisi AR, Mohajervatan A, Mehraein Nazdik Z. Mass Casualty Response to Mine Explosion: A Case Report in Iran. Health Emerg Disasters 2019; 4(3):173-8.

10. Page K. Blood on the coal: the effect of organizational size and differentiation on coal mine accidents. J Safety Res 2009; 40(2):8595.

11. Kowalski-Trakofler KM, Vaught C, Brnich MJ,
Jansky JH. A Study of First Moments in Underground Mine Emergency Response. J Homel Secur Emerg Manag 2010; 7(1). doi:10.2202/1547-7355.1652

12. Karlsson S, Saveman B-I, Gyllencreutz L. The medical perspective on mining incidents: Interviews with emergency medical service [EMS] personnel. Int J Emerg Serv 2019; 8(3):236-46.

13. Finkelman RB, Wolfe A, Hendryx MS. The future environmental and health impacts of coal. Energy Geosci 2021; 2(2):99-112.

14. Annelli JF. The national incident management system: A multi-agency approach to emergency response in the United States of America. Rev Sci Tech 2006; 25(1):223-31.

15. Tyson JS, Bouldin ED. Using Preparedness Exercise Tools to Train Public Health Teams to Address Access and Functional Needs During Emergencies in Rural Appalachia. Health Secur 2020; 18(2):145-9. 